under the genus Citrus are listed eleven species and varieties together with certain 'unspecified' species. Following this list, which occupies 180 pages, are 68 pages of useful crop notes on certain species.

The authorities at the Royal Botanic Gardens, Kew, especially Sir Arthur Hill and Mr. H. C. Sampson, are to be congratulated on this very praiseworthy effort to "stimulate the trials of new crops, and more especially the trial of other varieties of crops already under cultivation". With this aim in view, it will prove indispensable to tropical and subtropical agriculturists; but we feel, apart from this, that if the general subject of botany were taught and studied as it should be, then as a reference list the brochure would be necessary to the equipment of every 'academic' botanist, for as a source of information and guide to further study it will prove invaluable to him.

\title{
Nutrition and National Health
}

$\mathrm{I}^{\mathrm{N}}$ the Cantor Lectures for 1936 before the Royal Society of Arts*, Sir Robert McCarrison presented a strong case for the fuller recognition of the importance of nutrition in determining the health and efficiency of human beings, as it has long been recognised in the case of domestic animals. Observations on the dietary habits of different races of men in India have convinced him that the kind of food habitually eaten is responsible not only for striking differences in physique, vitality and endurance, but also for equally striking differences in their susceptibility to diseases of various kinds. His numerous experiments in the laboratory have amply confirmed the field observations and have demonstrated the poor physique and increased liability to disease of animals reared on faulty diets similar in composition to those consumed by large sections of the populations both of India and of Western countries.

The analysis of the dietary factors concerned in the maintenance of good nutrition is proceeding rapidly, and new light is being shed on the origin of a great number of common human diseases and disorders. Insufficient supplies of mineral elements and vitamins have been shown not only to lead directly to the deficiency diseases, but also to be important predisposing causes to other diseases of infective or metabolic origin. Deficiency of one or more of the factors calcium, phosphorus and vitamin

- The Royal Society of Arts. Cantor Lectures, 1936. Nutrition and National Health: Three Lectures delivered before the Royal Society of Arts on February 10th, 17th and 24th, 1936. By Major Gen. Sir Bobert McCarrison. Pp. 56. (London: Royal Society of Arts, 1936.) 2s. $6 d$.
D, which dominate the calcifying processes of the body, is one of the commonest faults in Great Britain. Iron deficiency is responsible for a great deal of illhealth both among infants and among women of the child-bearing period of life. In parts of the world, iodine deficiency is concerned with the appearance of endemic goitre and its associated cretinism and deaf-mutism.

Though but few diseases caused directly by gross deficiency of specific food elements are commonly met with in Western countries, lesser degrees of dietary deficiencies are of great importance in determining the onset of some of the common illnesses of mankind. The geographical distribution of such diseases as tuberculosis, gastric and duodenal ulcer, rheumatism, nephritis and heart-disease in India suggest that nutrition plays an important part in their causation. There is no reason for supposing that nutrition is not an equally important factor in determining the susceptibility of individuals in Western countries to similar diseases.

There is increasing evidence that in Great Britain faulty nutrition is by no means a rarity and is not confined to the poorest classes of society. Two measures are strongly recommended to bring about that raising of the standard of nutrition which should result in a general improvement in physique and a lessening of the amount of disease. The first is the laying of greater emphasis by the medical schools on the instruction of their students in the general principles of nutrition; the second is the teaching of the elements of nutrition to school-children.

\section{Measurements of Temperature at Great Heights}

DROFEsSIONAL Note No. 67 of the Meteorological Office, Air Ministry, by L. H. G. Dines, entitled "The Rates of Ascent and Descent of Free Balloons and the Effects of Radiation on Records of Temperature in the Upper Air", deals with two problems in connexion with the measure. ment of temperature at great heights in the atmosphere that are more closely related than they appear to be at first sight.

The records of upper air temperature with which the writer is concerned are those obtained at meteorological stations in Great Britain with the aid of the simple mechanism known as the Dines balloon meteorograph, that has been in use with only slight modifications for twenty-seven years.
This apparatus will only indicate air temperature provided that it is not heated directly by solar radiation, or radiation from any other source, and is not chilled by the loss of its own heat by radiation, and, further, provided that the air with which it comes in contact has not been warmed or chilled by contact with any of the auxiliary apparatus- such as the balloon. When an ascent is made during the daytime, the balloon may become strongly heated by the intense solar radiation encountered at very high altitudes above cloud-level, but the meteorograph is suspended 40 metres below the balloon and therefore should not be affected; it is itself shielded from the sun by being mounted inside a polished metal cylinder, open at its ends, the ascent of the 